\title{
Prediction of Excitation Angles for a Switched Reluctance Generator using Artificial Neural Network
}

\author{
Pairote Thongprasri \\ Faculty of Engineering at Sriracha, Kasetsart University Sriracha Campus, \\ 199, Sukumvit Road, Tungsukla, Chonburi 20230, Thailand
}

\begin{abstract}
This paper presents a method to determine excitation angles for a Switched Reluctance Generator (SRG) by using Artificial Neural Network (ANN). The ANN model consists of the feed-forward neural network and the back-propagation learning with a linear activation function (the linear function) and a nonlinear function (the hyperbolic tangent). The ANN model with two layers; the hidden layer and the output layer, is derived from the current and flux linkage of the SRG. The SRG model is built from the magnetization curve which the flux linkage versus current at different rotor positions is analyzed from the finite element method (FEM). An 8/6 SRG was set up to validate the proposed ANN method.
\end{abstract}

Keywords: artificial neural network; feed-forward; back-propagation; hidden layer; output layer

\section{INTRODUCTION}

Advantages of SRGs are fault tolerance, high robustness, and high efficiency. The SRG has remarkable characteristics which employs as a variable speed generator [1]. However, the SRG requires a position sensor for the commutation of the stator phases in synchronism with the rotor position and its nonlinear electrical behavior provides a high torque ripple [2]. Finite Element Method (FEM) is the accurate solution to the model problem in SRG. However, FEM is a time consuming process and has a lot of data. An optimized design of the SRG for maximum output power is proposed [3]. The system based on a simple controller is proposed that the optimal control angles are determined online [4]. A back-propagation neural network is a multilayer feed forward network trained by back propagation algorithm. The objective is to train the network to achieve a balance between the ability to respond correctly to the input patterns. The training of a network by backpropagation involves three stages; the feed-forward of the input training pattern, the calculation and back-propagation of the associated error, and the adjustment of the weights. After training, application of the net involves only the computations of the feed-forward phase. A multilayer net (with one or more hidden layers) can learn any continuous mapping to an arbitrary accuracy.

The proposed method in this paper utilizes FEM and Artificial Neural Network (ANN). A model of a SRG based on MATLAB/Simulink depending on the flux linkage and the inductance obtained from FEM. A training data set is generated by control parameters of the SRG. Neural mapping used to predict the excitation angles after good training.

\section{OPERATION OF SWITCHED RELUCTANCE GENERATOR}

The SRG structure is double protruding pole. The SRG has steel laminations on the rotor and stator as shown in Fig. 1 that there are no windings or permanent magnets on the rotor. The operation of SRG depends entirely on synchronized excitation of the set of stator windings to create continuous rotation of the rotor poles. When the switches S1 and S2 are turned on, the windings on the stator are excited by the outer circuit, and the electrical energy and mechanical energy provided by exterior circuit are converted into magnetic field energy. When the switches S1 and S2 are turned off, nevertheless the diodes D1 and D2 are turned on. The magnetic field energy and mechanical energy are converted into electricity energy to the load.

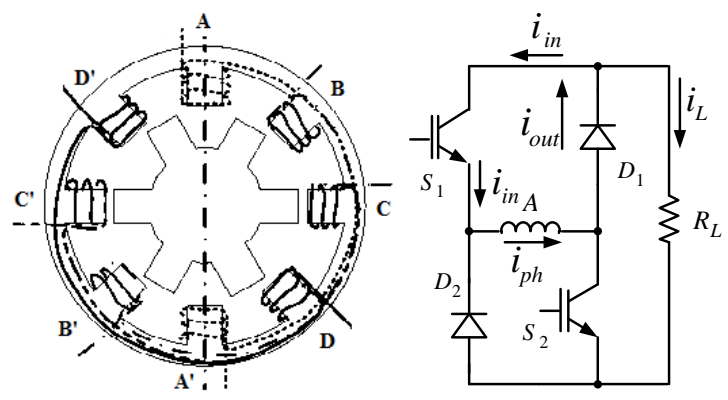

Figure. 1. 8/6 SRG structure (left) and its converter (right)

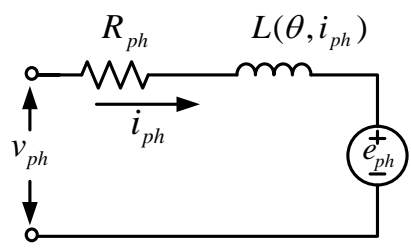

Figure. 2. Equivalent circuit of one phase SRG

The equivalent circuit of one phase SRG is shown in Fig. 2 that the phase voltage can be expressed by

$$
v_{p h}=R_{p h} i_{p h}+\frac{L\left(\theta, i_{p h}\right) d i_{p h}}{d t}+\frac{d L\left(\theta, i_{p h}\right)}{d \theta} \cdot i_{p h} \cdot \omega
$$

where:

$R_{p h}$ is the phase resistance

$i_{p h} \quad$ is the phase current

$L \quad$ is the inductance

$\omega \quad$ is the rotor speed. 
In this paper, the value of parameter of the candidate 8/6 SRG is shown in Table 1. The characteristics of flux linkage versus the current and rotor position of the SRG can be determined using the Finite Element Method (FEM) as shown in Fig. 3. The relationship between the flux linkage at the aligned and unaligned positions can be obtained from the FEM and is shown in Fig. 4. The relationship between the flux linkage and the phase current at different rotor positions is shown in Fig. 5 .

Table 1. The value of parameter of the candidate SRG

\begin{tabular}{|l|c|}
\hline \multicolumn{1}{|c|}{ Parameter } & Value \\
\hline Outer diameter of stator & $150 \mathrm{~mm}$ \\
\hline Inner diameter of stator & $70 \mathrm{~mm}$ \\
\hline Stack length & $70 \mathrm{~mm}$ \\
\hline Shaft diameter & $24 \mathrm{~mm}$ \\
\hline Length of air gap & $0.5 \mathrm{~mm}$ \\
\hline Stator pole arc & $22^{\circ}$ \\
\hline Rotor pole arc & $24^{\circ}$ \\
\hline
\end{tabular}

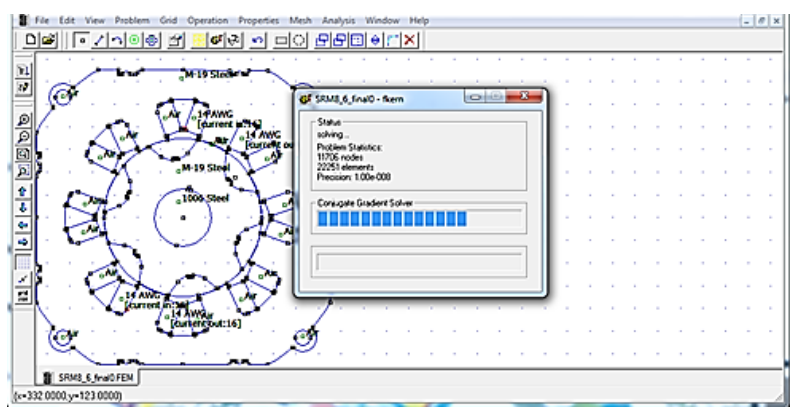

Figure. 3. Finite element method
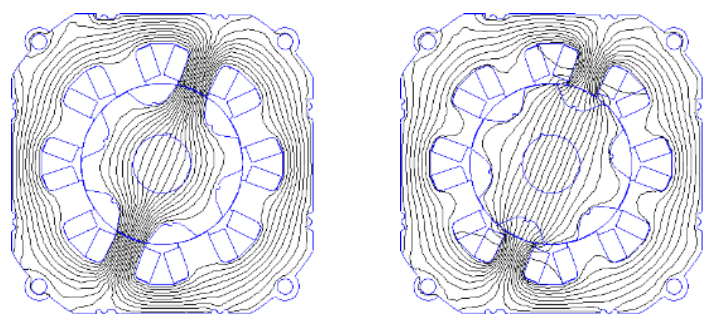

Figure. 4. Aligned (left) and unaligned (right) rotor positions

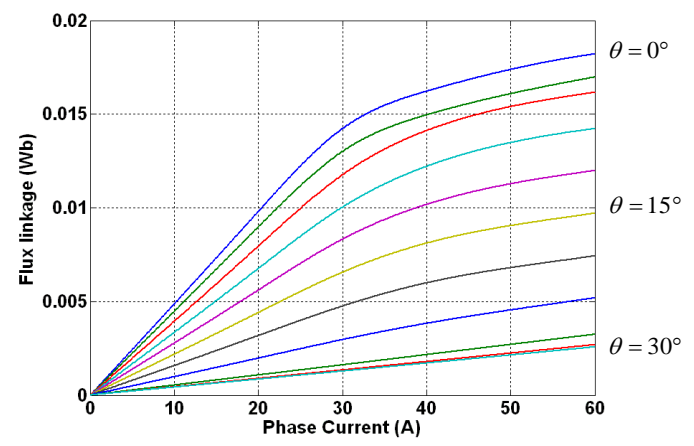

Figure. 5. Characteristics of flux linkage versus current and rotor position
The mathematical model of the phase current of the SRG is shown in Fig. 6 which is obtained using Eq. (1).

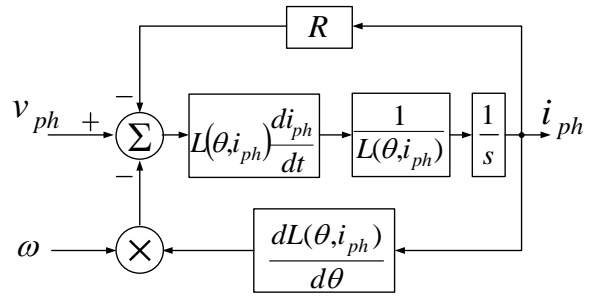

Figure. 6. Block diagram for mathematical model of the phase current

\section{ARTIFICIAL NEURAL NETWORKS}

Artificial neural network (ANN) is computing systems whose structures are inspired by a simplified model of the human brain [5]. In Fig.7 describes a typical 3-layer feed-forward ANN. It consists of input layer, output layer and hidden layer. Activation signal of nodes in one layer are transmitted to the next layer through weights which either attenuate the signal [6]. The value of the weights in a supervised ANN is determined through the iterative training process. ANN output is compared with true output from training data set, and then the weights are adjusted incrementally to make the error minimum. Several learning methods have been developed such as back-propagation, Levenberg-Marquardt [7].

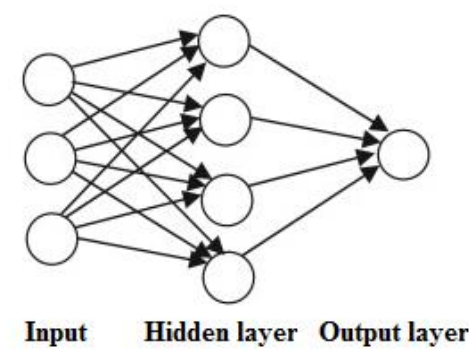

Figure. 7. Typical 3-layer feed-forward ANN

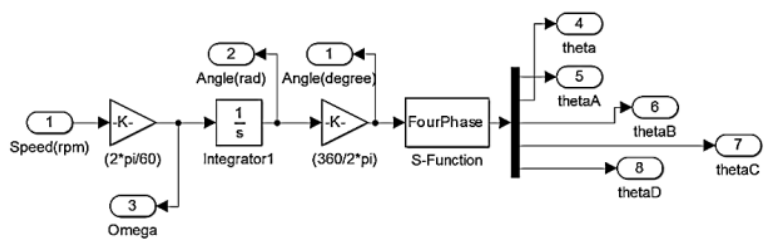

Figure. 8. Block diagram for mathematical model of the rotor position

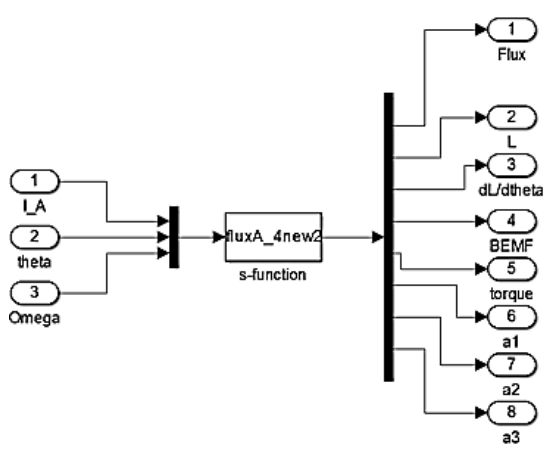

Figure. 9. Block diagram for mathematical model of the flux linkage 


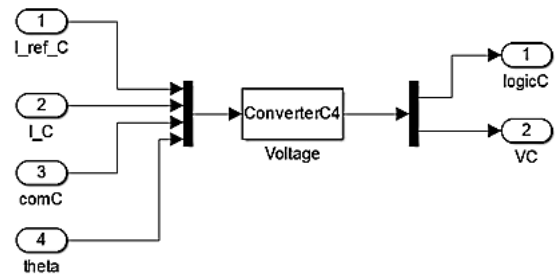

Figure. 10. Block diagram for mathematical model of the converter

The SRG model using FEM data consists of the rotor position model, the flux linkage model, and the converter model as shown in Figs 8-10, respectively. These models are used to simulate to collect data of the control parameters in different conditions. These data are used to train the ANN model. The mathematical model of inductance is shown in Fig. 11. The inductance based on the mathematical model and the block diagram to calculate of the SRG model are shown in Fig. 12 and Fig. 13, respectively.

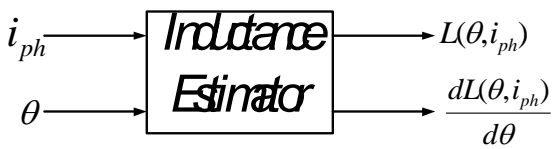

Figure. 11. Block diagram for inductance estimator

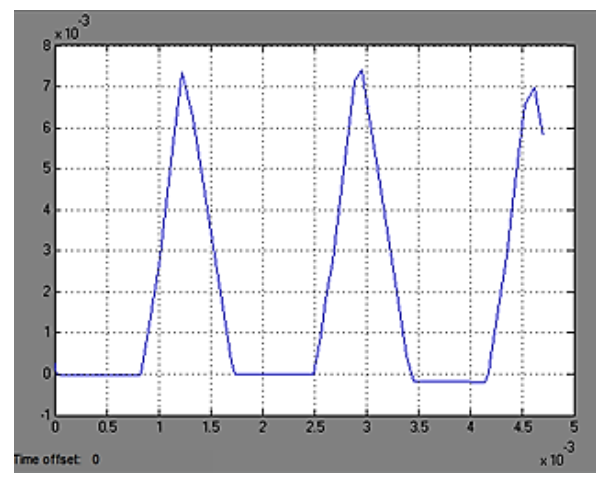

Figure. 12. Inductance based on the proposed model

Torque of the SRG can be given as

$$
T_{e}=\frac{1}{2} \cdot i_{p h}^{2} \frac{d L\left(\theta, i_{p h}\right)}{d \theta}
$$

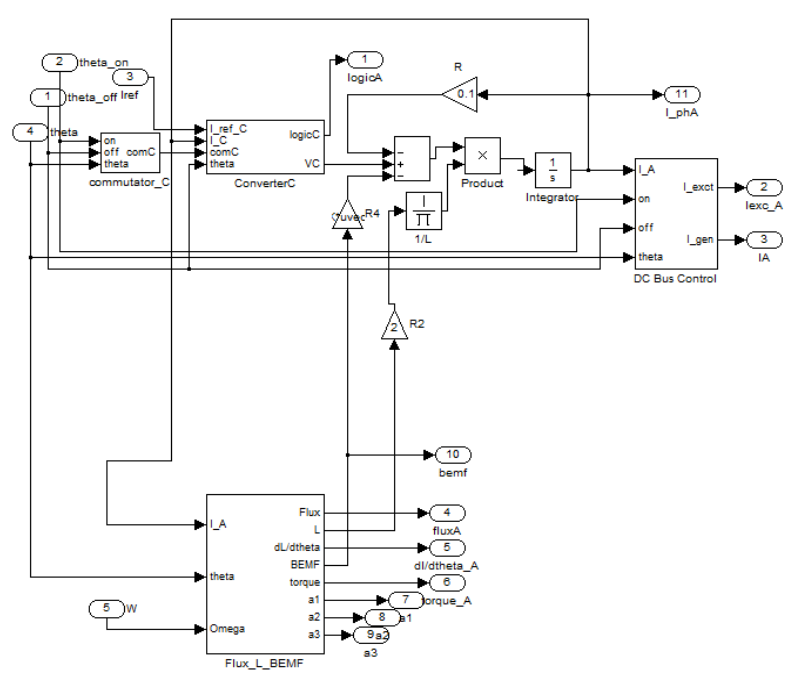

Figure. 13. Block diagram for calculation of the SRG

\section{SIMULATION AND \\ EXPERIMENTAL RESULTS}

The 8/6 SRG system is shown in Fig. 14. The induction motor is used as the prime mover. A variable transformer with a rectifier is used as the constant DC bus voltage. The average torque of the generator is measured by a rotational torque transducer. The rotor speed and the aligned rotor position are detected by a resolver mounted on the SRG. One ohm resistor is used as the load. The schematic layout of the experimental setup is shown in Fig. 15.
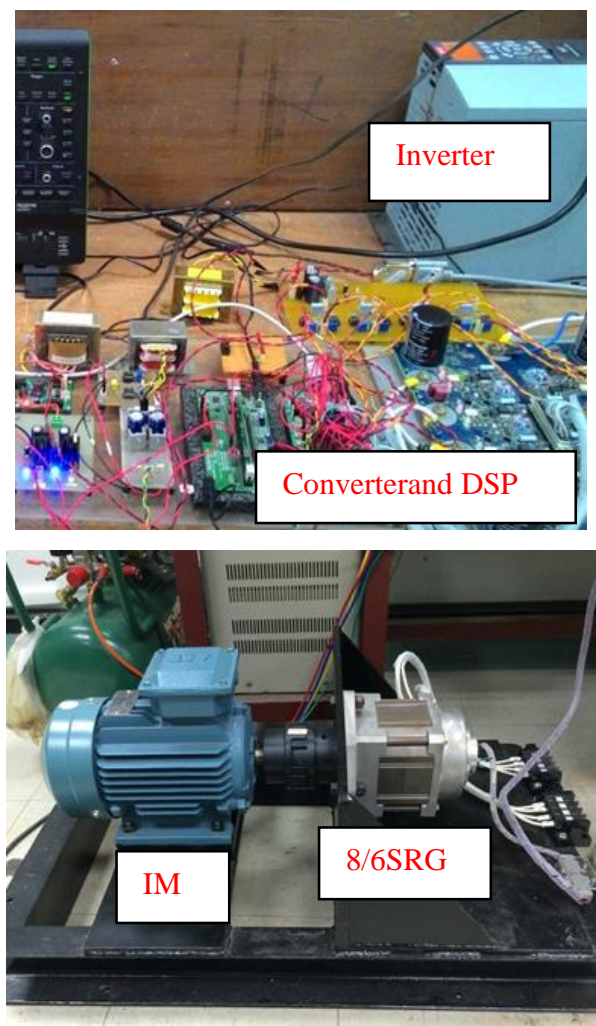

Figure. 14. 8/6 experimental Setup

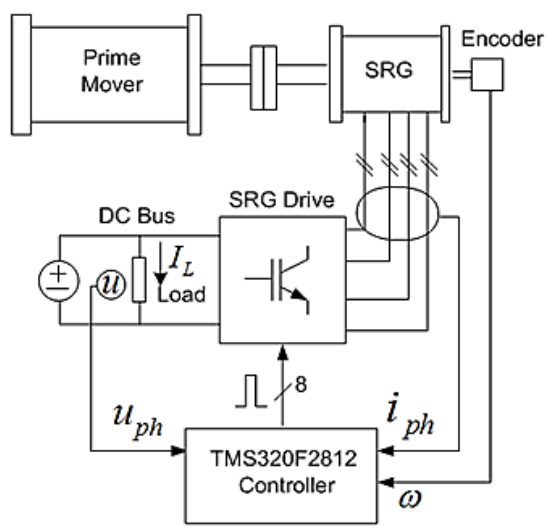

Figure. 15. Schematic layout of the experimental system

Fig 16 shows the rotor position of 4 phases of the SRG. Fig 17 shows the simulation results obtained from the mathematical model when the SRG is controlled at positions of turn-on $=0^{\circ}$ and turn-off $=13^{\circ}$. 


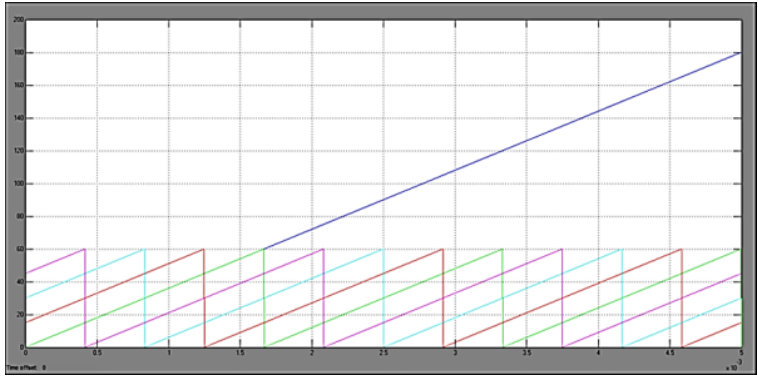

Figure. 16. Rotor position of 4-phase SRG

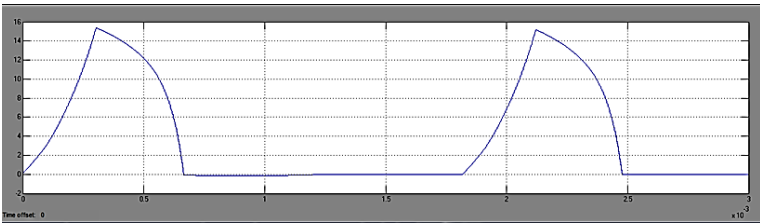

Figure. 17. Phase current shape at of turn-on $=0^{\circ}$ and turn-off $=13^{\circ}$

Data of the flux linkage, the rotor speed, the excitation angles, the DC bus voltage, and the phase current are used to train the ANN model. Ultimately; the ANN model only requires the data of the flux linkage and the phase current.

To validate the ANN model, the experiment results in 5 cases are shown in Table 2 when the proposed model of the SRG compare with the ANN model. And Figs. 18-22 show the results based on the proposed ANN model, the mathematical model, and the experiments. The waveforms of the phase voltage, phase current, the total torque (inverse), and the rotor position are described in the proposed model and the experiments.

Table 2. The value of parameter of the candidate SRG

\begin{tabular}{|c|c|c|c|c|}
\hline \multirow{2}{*}{ Case } & \multicolumn{2}{|c|}{ Turn-on $\left(^{\circ}\right)$} & \multicolumn{2}{c|}{ Turn-off $\left(^{\circ}\right)$} \\
\cline { 2 - 5 } & Model & ANN & Model & ANN \\
\hline 1 & 0 & 0.1472 & 15 & 15.45 \\
\hline 2 & 2 & 2.078 & 11 & 11.7 \\
\hline 3 & 3 & 3.209 & 15 & 15.33 \\
\hline 4 & 5 & 4.757 & 14 & 14.26 \\
\hline 5 & 8 & 7.758 & 16 & 15.64 \\
\hline
\end{tabular}
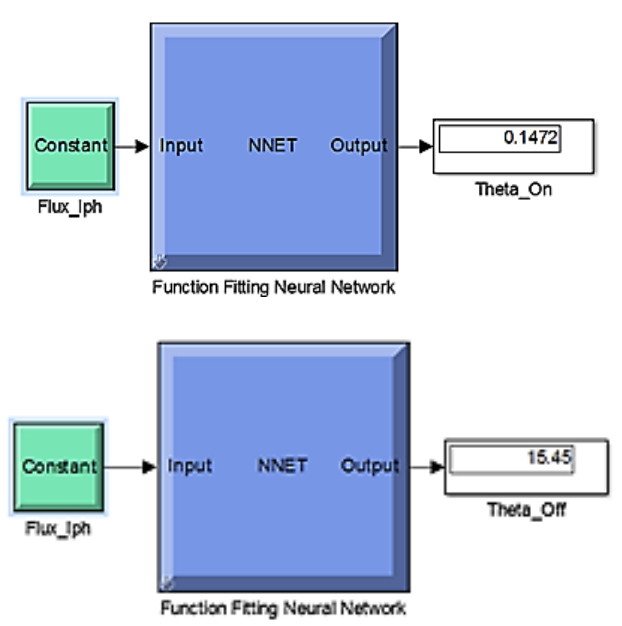
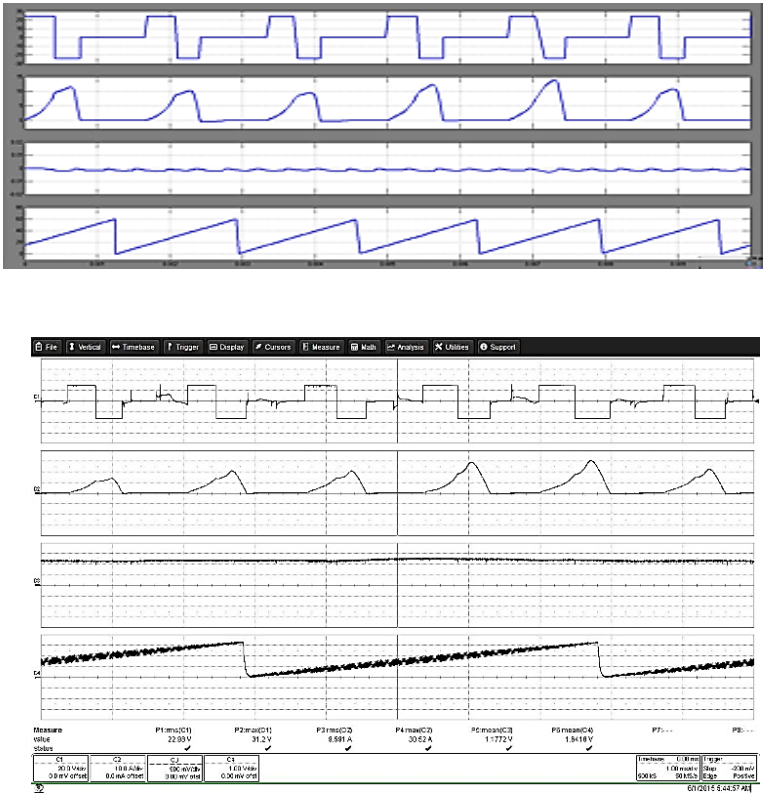

Figure. 18. Case 1 with turn-on at $0^{\circ}$ and turn-off at $15^{\circ}$; the proposed ANN (top), the mathematical model (middle), and the experiment
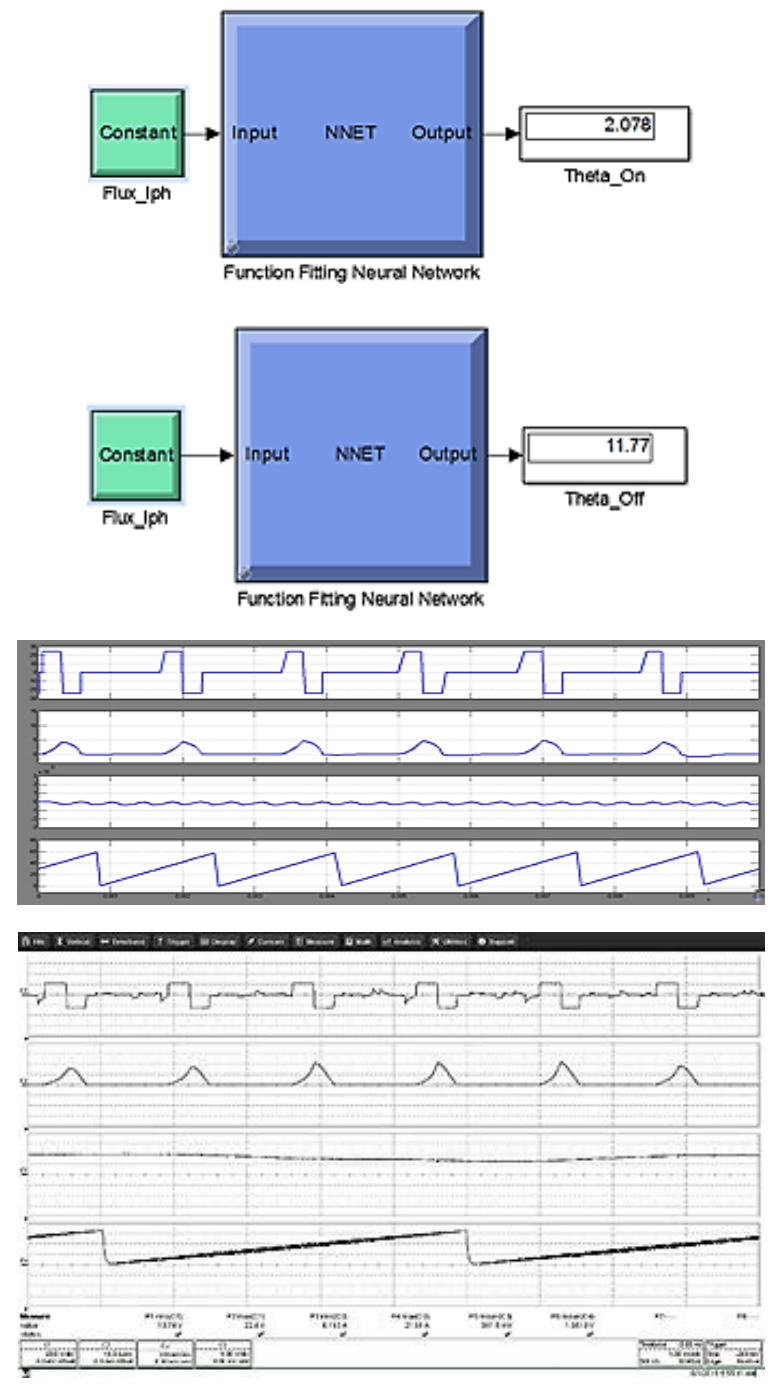

Figure. 19. Case 2 with turn-on at $2^{\circ}$ and turn-off at $11^{\circ}$; the proposed ANN (top), the mathematical model (middle), and the experiment 
International Journal of Science and Engineering Applications

Volume 6 Issue 10, 2017, ISSN-2319-7560 (Online)
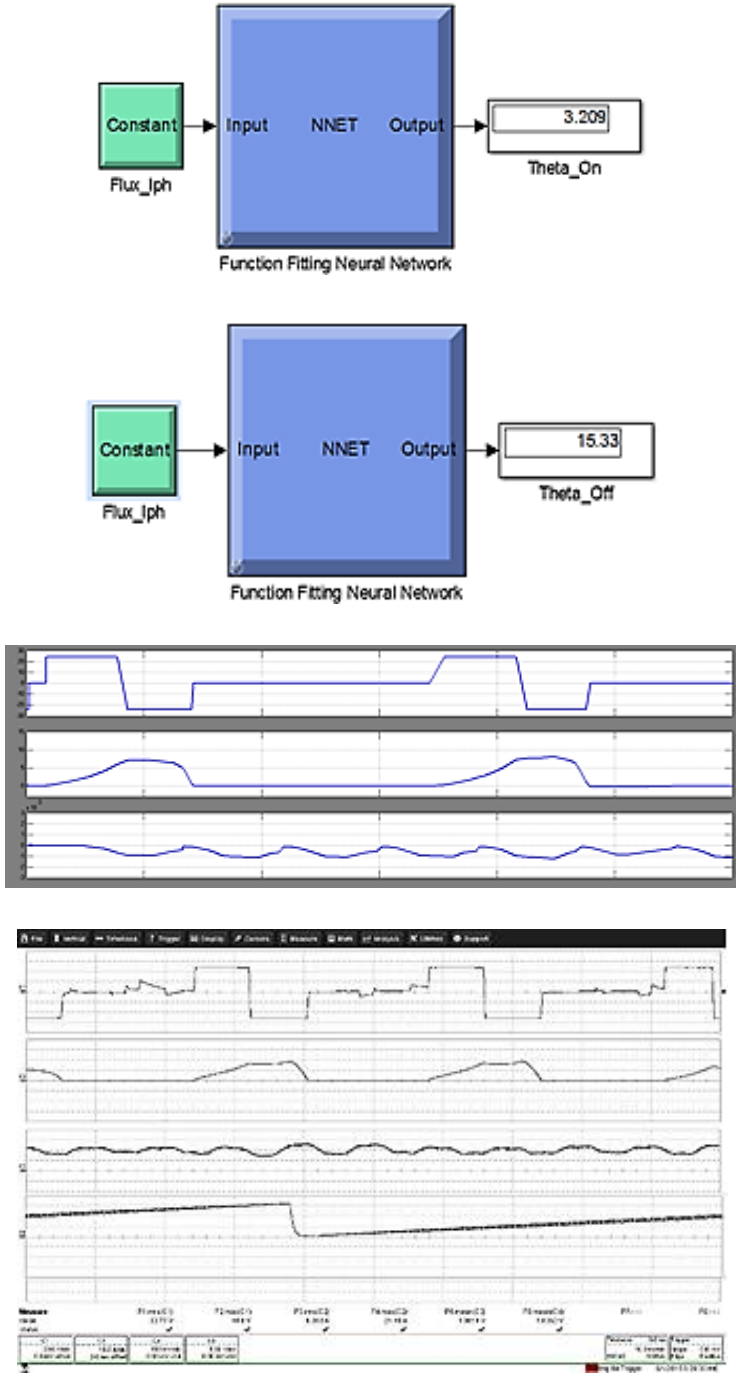

Figure. 20. Case 3 with turn-on at $3^{\circ}$ and turn-off at $15^{\circ}$; the proposed ANN (top), the mathematical model (middle), and the experiment
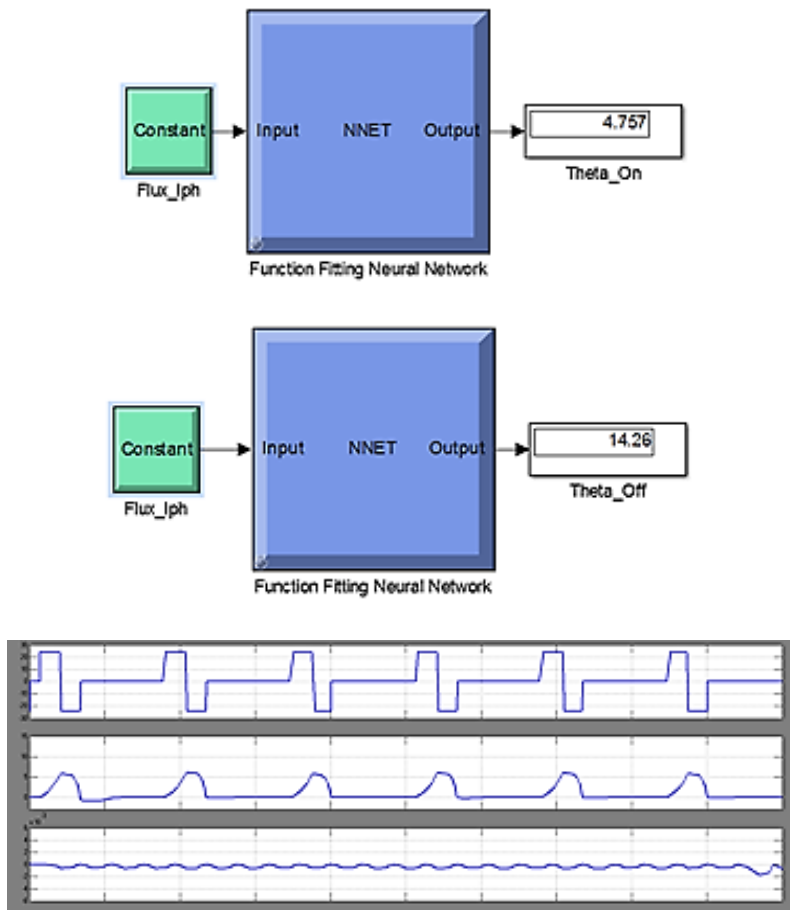

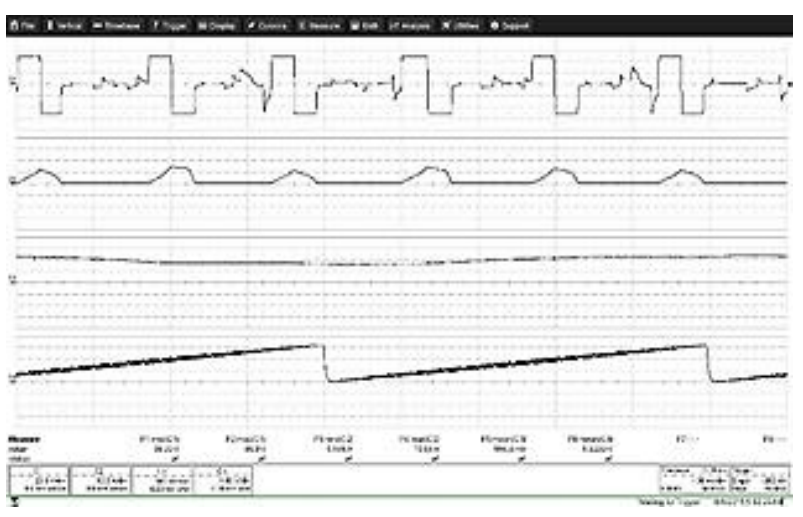

Figure. 21. Case 4 with turn-on at $5^{\circ}$ and turn-off at $14^{\circ}$; the proposed ANN (top), the mathematical model (middle), and the experiment
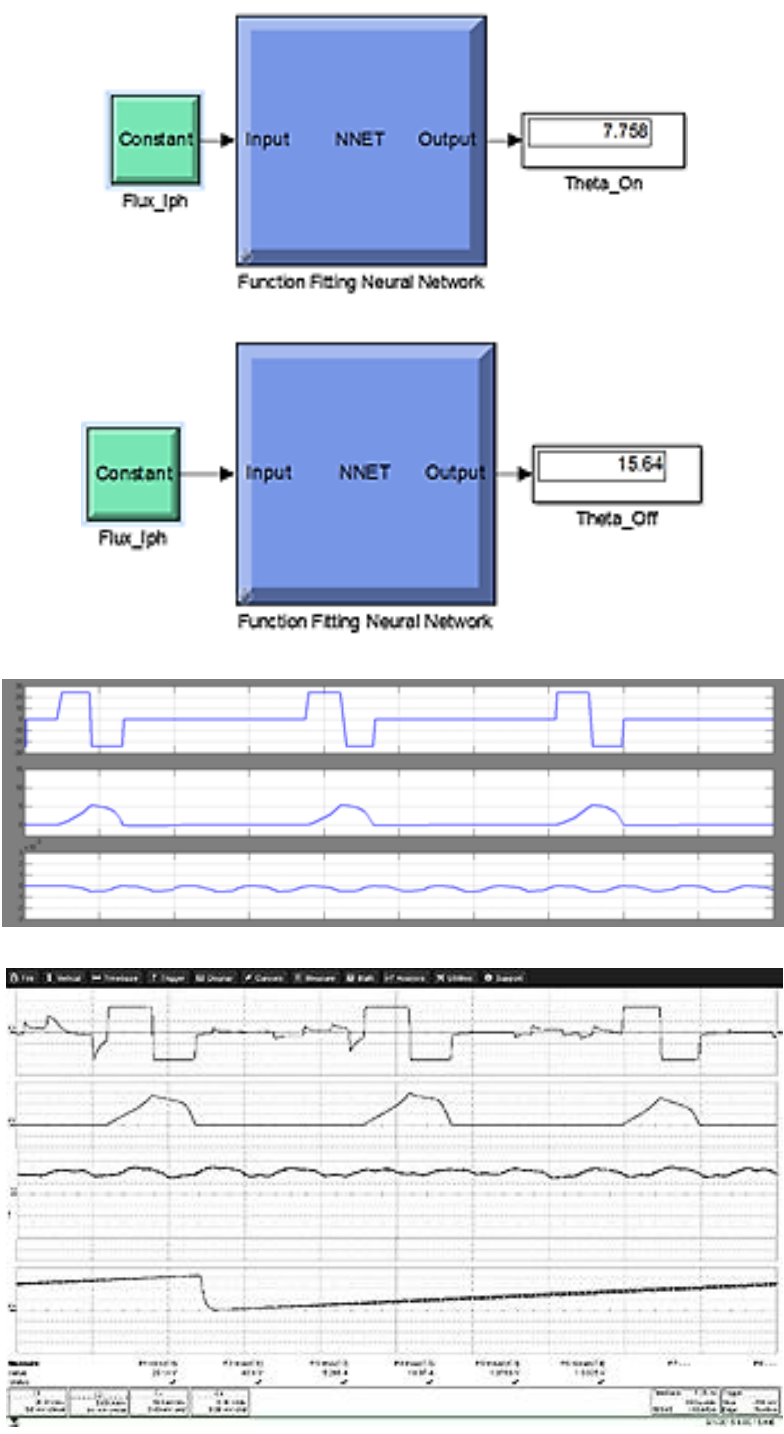

Figure. 22. Case 5 with turn-on at $8^{\circ}$ and turn-off at $16^{\circ}$; the proposed ANN (top), the mathematical model (middle), and the experiment

\section{CONCLUSIONS}

The ANN method for predicting the excitation angles of a SRG is proposed. The FEM is used to analyze the magnetization curve. The data obtained from the FEM is provided to build the SRG model. The model gives the 
position of excitation angles. The data of the flux linkage and phase current and control parameters are used to train the proposed ANN model. Regarding to results, the ANN can accurately predict to determine the excitation angles of the SRG. The average error is $4.9 \%$ compared to the mathematical model.

\section{REFERENCES}

[1] K.M. Rahman, S. Gopalakrishnan, Optimized, InstantaneousTorque Control of Switched Reluctance Motor by Neural Network, in Proc. IEEE IAS, vol. 37, 2001, pp. 904-913.

[2] E. Mese, D.A. Torrey, An approach for Sensorless Position Estimation for Switched Reluctance Motors Using Artificial Neural Networks, IEEE Trans. Power Electronics, vol.17. no. 1, 2002, pp. 66-75.
[3] P. Asadi, M. Ehsani, and B. Fahimi, Design and control characterization of switched reluctance generator for maximum output power, in Proc. IEEE APEC, 2006, pp. 1639-1644.

[4] R.G. Lopez and B. Diong, "Simplified control of switched reluctance machines for AC generation," in Proc. IEEE IAS, vol. 1, 2004, pp. 409.

[5] K. Yilmaz, E. Mese, A. Cengiz, Minimum Inductance Estimation In Switched Reluctance Motors By Using Artificial Neural Networks, in Proc. IEEE MELECON, 2002, pp. 152-156.

[6] H. Haykin, Neural Networlrs;A comprehensive Foundation, IEEE press, Macmillan College Publish Comp.,1994

[7] J.M. Zurada, Introduction to Artificial Neural Systems, PWS Publishing Company, 1992. 